\title{
El señor, el lirismo y la sangre. Una aproximación literaria y lingüística al harawi quechua de Kilku Warak'a en la poética de Yawar Para
}

\author{
The lord, the lyricism and the blood. A literary and linguistic approach to the
} Quechua harawi of Kilku Warak'a in the poetics of Yawar Para

\author{
Roxana Quispe Collantes \\ Universidad Nacional Mayor de San Marcos, Lima, Perú \\ Contacto: roxana.quispecollantes@unmsm.edu.pe \\ https://orcid.org/0000-0003-4321-823X
}

\begin{abstract}
Resumen
En este artículo analizo algunos recursos presentes en Yawar Para (Lluvia de sangre), un poemario publicado entre las décadas de 1960 y 1970. Mi objetivo es aproximarme a la poesía escrita por una de las cumbres de la expresión poética en quechua, Killku Warak'a (seudónimo de Andrés Alencastre Gutiérrez). En Yawar Para, el poeta alude al dolor como una fuerza que posibilita la transfiguración y que responde a la ausencia de los seres queridos, desde el llamado a la filiación y la evocación de la sangre. Ofrezco una lectura bilingüe de sus poemas, así como una mirada crítica a la mediación del poeta como voz de los runakuna (hombres quechua). El método empleado es el análisis de los recursos poéticos del autor para expresar su vinculación con el quechua. Evidencia un llaki phuyu (nube cargada de tristeza) que vierte una incesante y sangrienta lluvia sobre el runa.
\end{abstract}

Palabras clave: Poesía quechua; Análisis poético; Cusco; Killku Warak'a

\begin{abstract}
In this article I analyze some presents resources in Yawar Para (Blood Rain), a poetry book published between 1960 and 1970. My goal is to approach the poetry written by one of the summits of the poetic expression in Quechua, Killku Warak'a (pseudonym of Andres Alencastre Gutiérrez). In Yawar Para, the poet refers to pain as a force that enables the transfiguration and that responds to the absence of loved ones, from the call to filiation and the evocation of blood. I offer a bilingual reading of his poems, as well as a critical look at the mediation of the poet as voice of the runakuna (Quechua men). The method used is the analysis of the poetic resources of the author to express their connection with Quechua. Evidence a llaki phuyu (cloud loaded with sadness) that poured an incessant and bloody rain on the runa.
\end{abstract}

Keywords: Quechua poetry; Poetic analysis; Cusco; Killku Warak'a

Recibido: 16.11 .17

Aceptado: 14.04.18 


\section{Introducción y antecedentes}

Yawar Para (Lluvia de sangre) es el título del tercer poemario publicado por Killku Warak'a, seudónimo de Andrés Alencastre Gutiérrez. Nacido en Cusco en 1909, el poeta halló la muerte en circunstancias no esclarecidas en 1984. Su producción escrita abarca obras teatrales, poemas y estudios bilingües sobre el quechua. Así, cuenta con monografías, tesis y documentos en castellano (por ejemplo, Alencastre, 1961); obras teatrales donde suele recrear modismos locales del quechua en combinación con el castellano sureño (es el caso de Alencastre, 1955); y en su madurez promovió la escritura de un quechua "purista", que empleó exclusivamente en sus poemarios Taki Parwa (1955), Taki Ruru (1964) y Yawar Para (s. f.), en cuyas portadas aparece como Kilku Warak'a. Además, tiene un poemario bilingüe, Qori Hamanqay (Gonzales, 1999, p. 15). Los poemarios cuentan con pinturas y grabados del artista cusqueño Mariano Fuentes Lira, acompañados de una breve leyenda en quechua, de autoría del poeta.

Alencastre fue un escritor que vivió entre dos mundos, el mundo señorial de los mistis y el mundo menospreciado de los runakuna. Su vida estuvo atravesada por una serie de tensiones que asoman en diversos grados en su literatura. Algo similar ocurrió con Arguedas, aunque este descolló principalmente en la narrativa, mientras Alencastre cuenta con una valoración más elevada en la lírica, siendo considerado uno de los mayores cultores de la poesía quechua, por su capacidad para dotar al quechua escrito de mayor expresividad y fuerza (Acurio, 1976; Avendaño, 1993).

Cabe mencionar que Alencastre cultivó un quechua "mestizo" en su teatro y un quechua "puro" en su poesía. Abogó en ambos géneros por una escritura fonética del quechua, pero fue en la poesía donde empleó un quechua depurado, entendido como qhapaq simi ${ }^{1}$. Cuando publicó su primer poemario, en 1955, no existía un alfabeto adecuado del quechua escrito, pero había una larga tradición de escritura del quechua, heredado desde la colonia, a través del trabajo de los religiosos misioneros y doctrineros. En la biografía de Alencastre se entrecruzan tanto continuidades como rupturas con esta tradición, relacionadas con el hecho de haber cofundado la Academia de la Lengua Quechua en 1953 (Gutiérrez, 2009; 
Howard, 2007); así como con el hecho de descender de un linaje de terratenientes, marcado por la muerte del patriarca en $1921^{2}$.

Esta dualidad parece marcar su poesía quechua de manera contradictoria (Gonzales, 1999; Noriega, 2011), pero ello no se limita a su escritura en quechua. Como vecino influyente, dejó testimonio escrito en castellano de sus gestiones para la creación del distrito Kunturkanki, ubicado en las alturas de la provincia de Canas, en donde se estableció como fundador y primer alcalde (Alencastre, 1961). Resalto estos aspectos biográficos porque, en la sociedad peruana y particularmente en la sociedad andina cusqueña, el acto de la escritura es una marca de distinción, que distancia a los escritores quechuistas de la experiencia cotidiana de los runakuna, donde la expresión y transmisión del lirismo asume múltiples formas, que no recurren a la escritura occidental (Fernández, 1934; Flores, 2011; Mannheim, 1999).

La escritura en quechua constituye una arena inestable, un terreno movedizo en donde todo parece estar por discutirse. Incluso en la actualidad, escribir en quechua puede entenderse como un proyecto de reescritura de la historia, dada la dramática experiencia de los runakuna como sujetos despojados inclusive del nombre de su lengua. Como señala Ernst Middendorf:

El nombre de keshua o quechua es debido a los españoles y se empleó solamente algún tiempo después de la conquista, pero los naturales no lo usan y aún en nuestros días llaman su lengua Runa-simi, como en tiempo de los incas. (Citado en Noriega, 2011, p. 28)

Yawar Para, poemario publicado entre los años sesenta y setenta del siglo XX (no cuenta con una fecha exacta), ha sido descrito como un libro "profético y desgarrador", porque evoca temas dramáticos y parece augurar un porvenir sombrío, constituyendo "una mazorca lírica del que se desgranan la muerte, el pesimismo y el fantasma de su padre muerto que lo atormenta" (Gonzales, 1999: p. 15). El carácter profético es atribuible a la leyenda que rodea a la muerte de Andrés Alencastre, ocurrida en circunstancias similares a las de su padre, el terrateniente Leopoldo Alencastre. 
En la presentación de Yawar Para, Alencastre se anuncia en idioma castellano como un receptor privilegiado del sufrimiento de los runakuna, quien desde la cima de los Apus Ausangati y Salqantay ${ }^{3}$ brinda un testimonio poético "rotundo y viril" de la opresiva realidad del runa, manifestándose en su "treno" (lamentación y reflexión moral) como un intercesor auténtico del runa ante "los hombres llamados a forjar la anunciada Justicia Social”. Sin embargo, ¿hasta qué punto Kilku Warak'a expresa en su poesía la voz, el dolor o la experiencia del runa? A través del empleo virtuoso del quechua purista, suele usar términos que prácticamente no se hablan en las comunidades, por desuso principalmente, lo cual dificulta su traducción y comprensión. Además, el dolor y la experiencia que se expresan en sus poemas corresponden más a su propia realidad que a la del runa. E inclusive, la representación del mundo quechua en las pinturas que acompañan a los poemas puede interpretarse como elaboraciones de Mariano Fuentes Lira, más no son representaciones conocidas o empleadas por el runa en sus aspectos rituales, festivos y cotidianos.

En Yawar Para, el poemario es un objeto de arte en sí, un "artefacto" de fabricación artesanal, con folios unidos por una cuerda tejida con diseño andino. $\mathrm{Su}$ bella y sencilla bicromía resalta los contrastes entre elementos (tierra, agua) así como la relación entre la naturaleza (lo telúrico) y la cultura (lo cultivado). En la portada aparece en primer plano el nombre del poemario y en el extremo izquierdo el seudónimo de Alencastre. El diseño contiene motivos geométricos y agrarios estilizados. Los elementos son de dos tonalidades (rojo y negro) en un fondo crema. Mientras sus anteriores poemarios aludían en sus portadas al maíz (la flor, la mazorca), aquí la nota dominante son gotas en forma de "espiguillas de sangre" (partes de la flor del maíz) que caen como lluvia e inundan el escenario. De las gradas (de lo que parece un andén) desborda un rojo sangre que amenaza inundar los wachos (surcos de tierra en la chacra, representados triangularmente). $\mathrm{Y}$ en el interior de las gradas, una semilla parece augurar un nuevo comienzo.

El pintor ha evocado un simbolismo propio de una visión artística del mundo que no necesariamente corresponde a la cosmovisión runa, donde predomina la policromía y los temas alegres, la vida se representa con múltiples formas 
y representaciones geométricas, en donde diferentes principios de partición y homologación ordenan el espacio, el tiempo y la sociedad (Sánchez, 2014, p. 36). Esta no-correspondencia entre el arte y la realidad podría estar en la base del sentimiento que el qhapaq simi de la poesía de Kilku Warak'a produce en los lectores que conocen el quechua y la realidad de las comunidades.

\section{Objetivos, métodos, materiales y fuentes}

El objetivo es aproximarme a la poesía quechua escrita por un autor cusqueño, Kilku Warak'a, considerado como una cumbre representativa de la expresión en quechua. Para ello analizo uno de sus poemarios, Yawar Para, en donde identifico los recursos empleados por el autor para articular el dolor, la filiación y las figuras que utiliza para su transfiguración. Como este artículo se escribe para lectores castellano-hablantes, para el análisis transcribo en un lado estrofas y versos en el quechua del autor (columna izquierda) y las acompaño con traducciones al castellano hechas por mí en el lado opuesto (columna derecha). El método empleado es el análisis poético de los recursos que el autor utiliza para expresar su vinculación con la cultura quechua.

Este trabajo toma como base la revisión de la vida y obra de Kilku Warak'a, efectuada en el marco de mi investigación de tesis doctoral (véase la nota 2). La fuente principal es el poemario Yawar Para, no totalmente escrito en quechua, pues cuenta con una presentación en castellano hecha por el autor. No tiene traducción completa, ni hay entre los estudios que lo citan un acuerdo sobre la fecha exacta de su publicación, que suele ubicarse entre 1967 y 1972. Por ejemplo, en Wikipedia la fecha de 1972 coincide con la ofrecida por Odi Gonzales (1999). Sin embargo, Avendaño (1993) le atribuye el año de 1967, mientras que Ricardo González Vigil (2004) y la Antología Quechua del Cusco (Nieto, Vargas e Itier, 2011) optan por citarlo como sin fecha $a^{4}$. He optado también por este criterio, pues en el libro original lamentablemente no figura el año exacto de publicación.

A diferencia de los anteriores poemarios de Alencastre, que cuentan cada uno con 30 poemas en promedio y hasta una decena de ilustraciones interiores, Yawar Para llega a tener 42 poemas ordenados en numeración romana, pero solo 
4 ilustraciones, sin contar las de la portada y la contraportada. Contiene un total de 1258 versos de arte menor, distribuidos mayoritariamente en estrofas de $4 \mathrm{y}$ 6 versos, y en mucha menor cantidad de 5 y 7 versos; sin embargo, muestra una marcada preferencia por las estrofas de 4 versos, que son casi el doble de las de 6 versos. Hay también algunos efectos de repetición de sonidos que no siempre son regulares, aunque mantienen una estructura formal precisa. Tomaré para mi análisis poemas desde la noción de harawi, esto es, composiciones poéticas caracterizadas por manifestar un sentimiento adolorido, marcado por el pesar y la sensación de pérdida, y que son empleados por el autor para expresar sus sentimientos líricos en relación con su vivencia de la vida en los Andes.

\section{Escenario de dolor y transfiguración}

En Yawar Para, el poeta se transfigura en seres de la naturaleza, de manera análoga a los recursos que emplea la cosmovisión andina, cuyas divinidades se encarnan de manera constante y diversa en múltiples seres poderosos (Sánchez, 2014); así, Killku Warak'a se apropia del valor de los personajes naturales que lo acompañan. De este modo se protege cuando se siente vulnerable y triste, dejando de ser un hombre con sentimientos y emociones:

\begin{tabular}{l|l}
$\begin{array}{l}\text { P'atakiskhkamari } \\
\text { nuqqaqa kasqani, }\end{array}$ & $\begin{array}{l}\text { Entonces yo había sido } \\
\text { una espina que feroz muerde, } \\
\text { mana yacaspaymi, } \\
\text { sin saberlo } \\
\text { lliwta t'urpusqani. }\end{array}$ \\
\hline
\end{tabular}

Este recurso lo utiliza como arma para combatir el sufrimiento que acompaña su vida; y, contradictoriamente, para realzar su propio dolor, proporcionando sentimientos humanos a seres que naturalmente no los poseen.

La poesía de Killku Warak'a recurre así a una deshumanización de su existencia, se metamorfosea con la naturaleza para descender en la escala sensitiva y emocional; armarse de valor y poder confrontar a sus contendores, asimilando 
propiedades de la piedra, de las espinas, como armas que luchan contra la erosión, el paso del agua, la presión del viento, caídas, golpes, lluvia, fuego, frío, calor, soledad, desprecio, lágrimas, etc., como enunciados generales que caracterizan el dolor y la transfiguración. Y el poeta renace como un ser nuevo, fuerte e inconmovible, sin temor a una muerte que espera o acecha:

\begin{tabular}{r|l} 
Llakitan mikhuni & Mi alimento es la tristeza \\
wiqitan ukyani & y mi bebida son las lágrimas \\
caywan kallpacasqan & fortalecido con eso \\
aswanta kawsani, & vivo mucho más, \\
kikin wañuytapas & y hasta a la misma muerte \\
c'inllan suyashani. & en silencio la estoy esperando ${ }^{6}$.
\end{tabular}

Sin embargo, toda esta transformación y empoderamiento no devuelve la humanidad al poeta. Encuentro que la voz poética apela al sentimiento de la naturaleza como sensibilidad, y en la escala sensitiva y emocional se mimetiza con la naturaleza y se transfigura en elementos naturales que desnaturalizan la humanidad del autor. La poesía termina acentuando su soledad. Esta deshumanización es una figura que se aprecia especialmente en P'atakishka / Espina que feroz muerde:

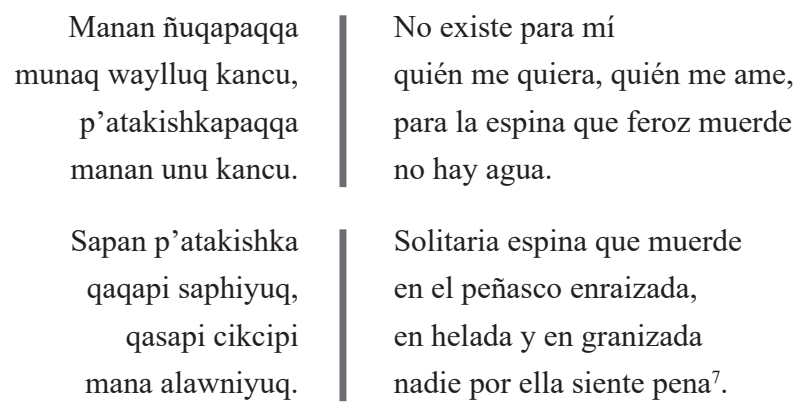

En P'atakishka, el autor se identifica con una espina salvaje, que crece en la puna. Evidencia en su similitud un continuo y persistente alegato en su defensa, admitiendo sentirse naturalmente negativo, indigno incluso de vivir en sociedad. Condenada simplemente a subsistir, sin conciencia de su condición, la p'atakishka vive marginada, ignorada por los hombres: 


\begin{tabular}{r|l} 
Hinakishkallapas & $\begin{array}{l}\text { Así pues espina como soy } \\
\text { t'ikanin icaqa }\end{array}$ \\
florezco también \\
kusicinitaqmi & y también alegro \\
pacapi kawsayta. & a todo lo que vive en la tierra ${ }^{8}$.
\end{tabular}

Pero al final la intención, pese a la voz doliente, es afirmarse positivamente, y el poeta se redime, emerge como una planta que puede alegrar toda vida; pero solo los humanos podemos manifestar sentimientos de alegría ante una flor, por lo que este símil universaliza naturalmente su redención. En otro poema, Rumiyapunin / Me estoy transformando en piedra, el poeta encuentra su fuerza en el impetuoso río, que recorre su propio camino y se impone a los obstáculos, en contraste con lo que ocurre en el camino de los que han sido despojados de humanidad?

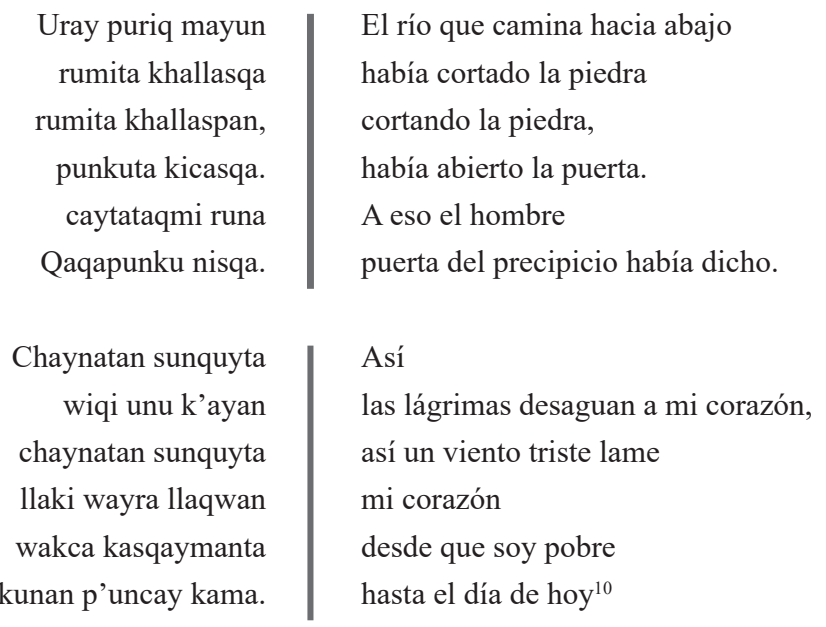

Es común señalar que en la concepción andina la naturaleza tiene vida; sin embargo, las figuras empleadas por Alencastre resaltan un aspecto excepcional del mundo andino: la soledad. Su transformación, esta vez en pórtico de piedra, le permite recibir el sufrimiento humano, su corazón se constituye en receptáculo de un dolor que se vuelve más intenso con la pérdida de la condición humana, al convertirse en wakcha (pobre). Pero el poeta al final emerge fortalecido, las lágrimas que lo deshumanizan se han convertido en su bebida (véase nota 6). 
Al tiempo que el autor se muestra fortalecido en sus poemas, evidencia la necesidad de adaptarse al dolor. Así, transforma las partes más sensitivas de su cuerpo para despojarse de sentimientos que lo atormentan; es decir, para rechazar a quienes lo sumen en ese dolor profundo. Esta lucha por la supervivencia (que conduce inexorablemente a la muerte y a la destrucción de un presente de caos y de opresión) se expresa en el lirismo de una realización anhelada que lo conducirá hacia una vida nueva y justa — según el autor-, desde los precipicios y lluvias de sangre donde casi siempre se encuentra, para irrumpir con supremo esfuerzo y representarse como un runa común, aunque pertenecía por su origen al estrato misti. Odi Gonzales le atribuye una dualidad contradictoria, entre su lenguaje poético y su vida en Canas.

Retirado ya de la docencia, el sexagenario Dr. Alencastre se instala definitivamente con su familia en "El Descanso" [...] [donde] habría de vivir intensos años ejerciendo el poder y la impunidad — no ajena a su casta de patrón y caciquepero también, hay que decirlo, consagrado al ordenamiento y corrección de sus entrañables waynos y poemas, en una actitud dolorosamente contradictoria; dos lenguajes irreconciliables: el discurso y los hechos que, por cierto, jamás convergieron en su espíritu. (Gonzales, 1999, p. 16)

En este proceso de construir su yo poético, expresa su desdén hacia la soledad con un clamor intenso que suena como el lamento de un runa desdichado, que intenta saber el porqué de sus pesares. Respuesta que puede hallarse en el recurso a la filiación, que está ligada con los temas de la sangre, la paternidad y el destino familiar.

\section{Filiación o genealogía del poeta}

Andrés Alencastre, Kilku Warak'a, escribió una poesía donde las pérdidas ocupan un lugar predominante. Las figuras a las que recurre para expresarse guardan correspondencia con el significado que atribuye a elementos que son naturales, como la sangre, pero que enraizados dentro de una significación cultural (que no es la de la cosmovisión del mundo andino) adquieren un sentido ambivalente. Así, 
su evocación y lamento por la pérdida genealógica se muestra en la preponderancia de la sangre como el vínculo que lo une a la figura paterna (el principal ausente), la figura materna (de quien se halló distanciado física y emocionalmente en su poesía), y una hija con sus tres nietos (que huyen de él, según sus poemas). Es decir, la constante alusión a la sangre puede interpretarse en cierto nivel como un anhelo de continuidad genealógica, que resulta imposible por las circunstancias de su biografía.

Cuando el poeta entraba a la pubertad, su padre, el latifundista don Leopoldo Alencastre, fue asesinado en una manifestación de violencia planificada durante el periodo turbulento de los años veinte del siglo pasado, donde "un sismo social" de rebeliones campesinas removió todo el sur andino. En este contexto, según el historiador Flores Galindo, los mistis temían que las movilizaciones indígenas restauren el Tahuantinsuyo. Pero se carece de fuentes que recojan el punto de vista de los campesinos. Así, por ejemplo, un propietario de la finca Viscochoni-Paucartambo denunció que una india, blandiendo un cuchillo, pretendió "victimarlo y beber chicha en su cráneo". Para este historiador, esta amenaza fue frecuente y formaría parte de la letra de una antigua canción guerrera supuestamente incaica (Flores Galindo, 2010, p. 221). Se resalta esta fuente porque se carece de testimonios indígenas. Sin embargo, puedo agregar que en la tradición oral cusqueña, la canción remite a la antigua rivalidad con los chankas, y es usada por las comunidades al referirse a los pueblos de la zona de Apurímac. No expresa un conflicto de indios contra gamonales.

El asesinato del misti Leopoldo Alencastre tuvo "un epílogo inesperado": la muerte, décadas después, de su hijo Andrés Alencastre, quien terminó con la casa incendiada y su cuerpo convertido supuestamente en objeto de rituales sangrientos (Flores Galindo, 2010, p. 225; Gonzales, 1999, pp. 16-17). Hay quienes encuentran vaticinios de su deseo de ser sacrificado en la siguiente estrofa del himno que compuso en castellano para Kunturkanki: "Aun después de muerto pondré mi cadáver, cual fecundo abono para que florezcas" (Alencastre, 1961).

En Yawar Para, el poeta canta al padre muerto y hace explícita mención a su madre (poemas VII y XIV), a un hermano ausente (poema XXXIV) al que suplica 
que no le maltrate en nombre de sus padres fallecidos (poema XXVII), y realiza una especial reiteración a la hija que abandonó el nido paterno con sus tres hijos para nunca regresar (poemas VIII, XIII, XXI, XXVIII y XXXVIII). Aunque los lazos de sangre son el símbolo predominante, en su poética también aparecen figuras sustitutas paternas, en los maestros que estimaba como segundos padres (poemas III, XXIII y XXXI). También evoca a un doctor cusqueño, muerto tras ser apresado en el "Sepa"11 (poema V).

La ausencia del padre es la nota dominante en los poemas XXII y XXV. El poema XXII, MASHKASHAYKIN TAYTALLÁY / Te estoy buscando padre mio, articula el pasado con un presente donde el dolor que provoca la ausencia paterna se manifiesta en las fuerzas naturales, e incluso en las estructuras del hogar, destruidas por las fuerzas del tiempo y la memoria:

$$
\begin{array}{r}
\text { Maypitaq kanki taytalláy } \\
\text { phuyumancu llanthumancu } \\
\text { iphumancu, wayramancu } \\
\text { qunqaylla tukurqapunki } \\
\text { Ripusqayki pacamanta } \\
\text { wasincis uspha pirkayuq, } \\
\text { ichunpas hallp'añan tukun } \\
\text { punkunkunataq ñawsayan. }
\end{array}
$$

Donde estás padre mío, a nublado, a sombra a garúa, a viento sorpresivamente te transformaste.

Desde el momento en que te fuiste nuestra casa tiene paredes de ceniza, hasta su paja ya tierra es y sus puertas enceguecieron ${ }^{12}$.

La filiación se manifiesta desde una ligazón establecida entre la paternidad y la muerte. En este poema se visualiza el deseo de una identificación plena del hijo con el padre. En sus versos se mimetiza con él, lo transfigura, y su identificación lo lleva a desear la misma muerte. Convierte su final en presagio del suyo, sombrío anuncio de la crisis que conlleva la desaparición un patriarca:

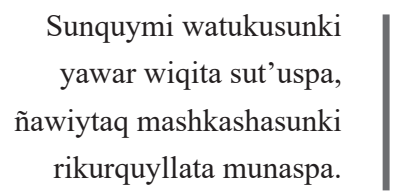

Goteando lágrimas de sangre

mi corazón te presagia,

y mis ojos te buscan

deseando solo verte. 
Sutiykin taytalláy aswan

kikin chilinaypi kashan, qhari sunquykiq kallpantaq sunkuyta kawsaricintaq.

Tayta wañuyka wañuymi mallkin kunpakun wiñaypaq, rurunkunatapaq t'akakun mana puquyta atispa.
Tu nombre padre mío se encuentra en mi misma médula espinal, la fuerza de tu corazón varonil revive a mi corazón.

La muerte de un padre es morir árbol que se tumba para siempre, sus frutos se desparraman sin poder madurar ${ }^{13}$.

Es decir, no hay una identificación con un colectivo, ni con un grupo en particular. La voz poética es la voz del poeta, Kilku Warak'a es Andrés Alencastre, hijo y padre, poeta y terrateniente. Existe entonces una referencia constante a la función paterna, que utiliza motivos líricos de la literatura indigenista (reproduciendo una percepción del mundo andino como un escenario agreste y violento) que remarcan su propia individualidad, pero que justifica como intermediación de la voz del runa. Ello se explicita en el texto en castellano, realizado por él, en su prólogo a Yawar Para:

El Ausangati y el Salqantay son mis antenas receptivas. Yo escucho en sus cimas, la queja de los hombres que sufren y que piden, pero esta petición justa y tenaz, recibe en respuesta, solamente, lluvia de sangre y ríos de lágrimas. Esta cruenta realidad canta YAWAR PARA, en treno rotundo y viril, a fin de ser escuchado por todos los hombres llamados a forjar la anunciada Justicia Social. (Killku Warak'a, s.f.)

Sorprende la cantidad de opiniones encontradas sobre Kilku Warak'a, a menudo por errores que inducen a confusión sobre su identidad. Por un lado, se le denomina "cantor indio", "indígena ciego" y él mismo se califica como harawikuq ${ }^{14}$; y por otro lado se le reconoce como "señor de indios", "mestizo", "latifundista", entre otros términos. No se le califica como indigenista, salvo en Noriega (2011) que ubica su obra en el discurso "señorial indigenista". Lo cierto es que hay cierto consenso en atribuirle la capacidad de representar fielmente al hombre andino y a su idiosincrasia. En una antología de la poesía cusqueña, se exalta a Kilku Warak'a de este modo: 
Paymi llaqtaq nunan, mana tukukuy sonqo takichiq arawiku; aqopanpakunapi aqomantapas mana tukukuqku llaqtaq sonqon / Él es el alma del pueblo, un corazón interminable que canta poesía; y así como en los campos de arena, y como la arena interminable el corazón del pueblo. (Avendaño, 1993, p. 444. / Traducción propia).

No obstante, los problemas y cuestionamientos que aparecen en Yawar Para se expresan en el ámbito personal nuqa o familiar nuqayku, distante del nuqanchis que alude al sentido colectivo de los runakuna. Es la autoridad paterna/patriarcal la que aparece cuestionada, en crisis, y es ante esta situación que el poeta añora un tiempo mejor, que anhela restaurar simbólicamente con su poesía:

Kukulilla, kukuli urpilla manañas q'isaykipicu kanki, mallkillaykiñas waqashan wayrawan maywiykukuspa.

Maytataq phalaripunki tuya piwantaq q'utucikunki qanqa kutimpuy kutikanpullay warma waqaqmi ñakasunkiman wiñay.
Palomita, paloma avecilla, dice que ya no estás en tu nido, solo tu árbol está llorando batiéndose con el viento.

A dónde te has volado calandria con quién te hiciste engañar tú regresa, solo regresa jovencita quien llora podría maldecirte eternamente ${ }^{15}$.

En Kutinkampullay / Solo regresa, el autor remarca la adhesión a la filiación con su hija. Implorando su retorno, la compara con un ave desprotegida, que deja su nido por engaños y se expone voluntariamente a ser una presa. Suplica su regreso, sin mencionar la causa de la partida, ni los motivos de la deserción, erigiéndose en cambio como único protector de la engañada, a quien provee y promete cobijo y hogar, pero a quien finalmente en el poema amenaza con maldecir si no vuelve.

El harawi de Kilku Warak'a transmite entonces un amor profundo por sus seres queridos, pero a la vez un vacío rotundo y difícil de cerrar. Con un clamor insustituible muestra las intimidades de su alma, donde yace el dolor de la ausencia. Hija y nietos se alejan, cual frutos dispersos, pedazos arrancados de su cuerpo, y el poeta espera que retornen al lugar del que nunca debieron apartarse. 


\section{Escritura y recursos lingüísticos}

La poesía escrita en quechua de Kilku Warak'a se relaciona con la reivindicación purista del quechua como idioma y como cultura ancestral. Noriega (2011) identifica varias tradiciones quechuistas de uso del quechua, y ubica a $K i l k u$ Warak'a como una manifestación identitaria "desdoblada", tensionada entre un “discurso señorial indigenista", cuyos orígenes se remontan al siglo XVII, y el “discurso poético migrante” del siglo XX (Noriega, 2011, pp. 85 y 109). Más allá de las confusiones que pueden generar las clasificaciones (como el hecho de considerar a Alencastre dentro del "indigenismo"), lo particular en Yawar Para es que en su poesía quechua se distingue un conjunto de símiles y giros metafóricos que contribuyen a la belleza de sus harawi. Muestra, además, un genio creador de palabras fusionadas para expresar su lenguaje poético.

A pesar de su singular estilo de graficar el quechua, la lectura atenta permite captar al conocedor del quechua, aunque con dificultades para comprender y traducirlo, aquello que quiere expresar. Se requiere un dominio avanzado del quechua y especialmente del denominado Qhapaq simi, cuya elaboración está ligada a la emergencia de un heterogéneo proyecto intelectual cusqueñista, que no está exento de contradicciones y disputas. ${ }^{16}$ El estudio del Qhapaq Simi requiere profundizarse en el plano histórico, literario, lingüístico y semiótico. ${ }^{17}$ Para ilustrar lo contradictorio que puede ser su empleo, puede servirnos la aparición dual del poeta en Yawar Para, como Kilku y como Kilko.

\section{¿Kilku o Kilko Warak'a?}

En Yawar Para, Alencastre firma su autoría en la portada como Kilku Warak'a, en coherencia con el quechua de tres vocales (trivocálico: a, i, u) por el que abogaba en sus obras. Sin embargo, en la contraportada aparece firmando como Kilko, es decir, presuntamente asumiendo la posición pentavocálica de la Academia Peruana de la Lengua Quechua. Pero más allá de la lingüística, su propuesta de escritura articula lo simbólico (lo Inca) con los recursos expresivos (el tejer). Así, en el poema XXXVII, Qhapaq Runasimi / Poderosa lengua del hombre, hace 
alarde del incaísmo de su propuesta, glorifica la memoria del Tahuantinsuyo y, mediante la configuración del verbo away (tejido), compara la expresión literaria con la labor tradicional de hacer telares:

¡Ayupaycana Runasimi Hamawt'akunaq kamasqan, Harawikuqpa awanan Tawantinsuyuq quri q'aytun.
Majestuoso idioma del hombre Mandato eres de los maestros Tejido de los poetas Ovillo de oro del Tahuantinsuyo ${ }^{18}$

Ya desde su trabajo como profesor y con las publicaciones de sus primeros poemas, Alencastre mostró facetas comparables a las de Arguedas, de quien fue amigo e incluso padrino de bodas. De sus varias facetas ha dicho el filólogo e historiador Georges Dumézil:

[...] él es originario de la región de Langui, provincia de Canas, Cusco, donde tiene siempre su chacra [...]. Bajo el nombre de Kilku Warak'a (Grégoire la Fronde) ha compuesto dramas y poemas, de los que se han publicado pocos. En 1951, en el concurso internacional de poesía qhiswa de Cochabamba (Bolivia) ha obtenido el primer premio, con una bella obra, Illimani. (Dumézil \& Alencastre, 1953, p. 1) ${ }^{19}$

Respecto a Arguedas, para autores como John Murra, "no hay una separación entre su etnología y su obra artística, de lo cual se daba cuenta" (Murra, 1983, p. 52), por lo que recomienda estudiar ambas facetas de su creatividad. Las complejas relaciones entre escritura literaria y formas de escritura etnográfica, presentes en la obra arguediana (Rowe, 1983), invitan además a un abordaje biográfico y riguroso de su lenguaje. En esa línea de interpretación, el joven Alencastre justificó, siendo estudiante universitario, un interés personal en conocer el mundo que ajustició a su padre: este hecho constituyó "un poderoso acicate para estudiar y comprender los hondos problemas socio-económicos que pendientes de solución se encuentran en el Perú" (Alencastre, en Flores Galindo, 2010, p. 224).

Sin embargo, la escritura trivocálica empleada por Alencastre en sus poemas reduce la rica expresión vocálica del quechua que se habla y canta en cada ayllu y en las comunidades andinas (indígenas y mestizas) dentro de su 
uso común. Ciertamente, una traducción no puede reflejar en un cien por ciento todo el significado, intención, manifestación, sentir del autor; pero puede brindar una aproximación al mensaje emitido, sin perder distancia. El problema de la traductibilidad continúa en vigencia. No se puede omitir, además, las relaciones de poder asociadas a la apropiación y ejercicio de la escritura en sociedades con pasados coloniales como la nuestra:

Los autóctonos, despojados legalmente (por la escritura) de sus tierras, sometidos a juicios por su 'idolatría', no pudieron ignorar por mucho tiempo el aparente poder-un poder delegado - de la escritura administrativa, diplomática o judicial. A veces llegaron, sin duda, a sobrevalorarlo, a atribuirle una eficacia poco menos que mágica. (Lienhard, 1992, p. 30) ${ }^{20}$

El poeta muestra en este poemario la creación de un quechua de estilo singular y fraccionado, en donde lingüísticamente omite grafías como la "h", fusiona y crea nuevas palabras $y$, en algunos casos, reemplaza las letras "m" por " $\mathrm{n}$ " $\mathrm{y}$ " $\mathrm{k}$ " por "q", o hasta puede aumentarle vocales a algunas palabras. Estos recursos lingüísticos se anuncian desde el inicio del poemario.

Como ejemplo voy a analizar el poema bilingüe KAWSAYNINCIS / Nuestra $v i d a$, texto parcialmente traducido, que no figura en el índice ni cuenta con numeración romana. El análisis nos permitirá ilustrar cómo el autor emplea el quechua. Este poema empieza con dos versos, que el autor no traduce, y que agruparé en dos columnas, correspondientes a la propuesta de escritura quechua del poeta (con mayúsculas en el original) y a la de la escritura convencional del quechua cusqueño. Traduzco estos versos como: "Nuestra vida en el mundo es el sueño de una noche entristecida".
Quechua literal del poeta Kawsaynincis LLAKITUTAPI MOSQOYMI PACAPI KAWSAYNINCISQA. Quechua convencional
Kawsayninchis
LLAKITUTAPI MUSQUYMI
PACHAPI KAWSAYNINCHISQA

En la columna izquierda, en el plano lingüístico se observa que el autor no solo ha eliminado el vocablo "h", sino que, a contracorriente de su propuesta de escritura trivocálica, ha incorporado la vocal "o". Y en la columna derecha, 
he resaltado en cursivas aquellas palabras que varían: puede verse que solo una palabra se mantiene igual. A continuación, presentaré los versos consecutivos del poema: en la primera columna en el quechua del autor; en la segunda columna, en la escritura convencional y en cursivas las palabras adecuadas; y en la tercera columna, la traducción de Alencastre.

\section{Quechua literal del poeta \\ YAWAR para llaki phuyu \\ llapa runa ñak'ariciq, caymi kanki sasa kawsay wiñaypas mana p'ucukaq. \\ Llapa c'iqmi kanakucun, musuq kausay paqaricun, k’apak canincasqa kawsay \\ llaqa runaq allinninpaq}

\section{Quechua convencional}

YAWAR Para, llaki phuyu

llapa runa ñak'arichiq, chaymi kanki sasa kawsay wiñaypas mana p'uchukaq.

Llapa ch'iqmi kanakuchun, musuq kawsay paqarichun, k'apaq chaninchasqa kawsay

llapa runaq allinninpaq.

\section{Traducción literal del poeta}

Lluvia de sangre nube de pena tortura de la humanidad esa eres vida difícil en todos los días sin fin.

Quemadas sean las tretas que la vida tenga un nuevo amanecer y esa vida sea justa y ordenada para bien de la humanidad.

La traducción del autor en algunos casos no se corresponde con lo escrito en quechua. En este poema, por ejemplo, se puede traducir c'iqmi (ch'iqmi) como desasosiego, incomodidad, desconfianza, pena. Pero Alencastre opta por pluralizar el término, como "tretas". En el poema XXX, Watuy / Presagiar, se evidencia su forma incompleta de escribir sustantivos (por ejemplo, escribe Saqsaywanpin en vez de Saqsaywamanpin) y dejar signos de admiración abiertos (en el verso de la tercera estrofa, escribe ¡Ay Pacakamaq por ¡Ay Pachakamaq!); así como redunda en la omisión de la "h", y el reemplazo de la "q" por la "k". Pongo en tres columnas los ejemplos en quechua y mi propia traducción.

\section{Quechua literal del poeta \\ SAQSAYWANPIN cikci cayashan, qhari sunquymi kayta watushan:}

\author{
Quechua convencional \\ SAQSAYWAMANPIN \\ chiqchi chayashan, \\ qhari sunquymi \\ kayta watushan:
}

Mi traducción
Está cayendo granizo
en Sacsayhuamán,
mi corazón de hombre
esto presagia ${ }^{21}$ :

Queda claro entonces que, para leer la poesía que nos presenta Andrés Alencastre Gutiérrez, el lector (bilingüe, o con dominio avanzado del quechua collao), tiene que tomarse su tiempo y tener cuidado especial y paciencia para 
reemplazar grafías, aumentar y acomodar consonantes y metáforas, al mismo tiempo que primero interpretar en la mente, las posibles palabras que nos quiere transmitir. Se requeriría un estudio detallado de su propuesta de escritura del quechua, ya que la Academia Peruana de la Lengua Quechua suele promover el sistema pentavocálico, y las tres vocales también son admitidas en el uso público convencional en el Cusco.

\section{Conclusiones}

He analizado el poemario Yawar Para (Lluvia de sangre) de Kilku Warak'a (Andrés Alencastre) a partir de tres aspectos significativos: transfiguración, filiación y escritura. Identifico una intencionalidad compleja en el empleo de algunas figuras (de naturalización y transfiguración), así como una evocación ambivalente a la filiación (a través del vínculo sanguíneo y patriarcal). También abordé el uso del Qhapaq Simi como propuesta de escritura para la poesía quechua del autor. Estos aspectos podrían articularse a través de dos nociones que ameritan de profundización: yawar (sangre) y harawi (poesía). La noción de yawar es polisémica en el mundo andino, en el poemario predomina una valencia negativa, asociada al dolor y la muerte, pero nociones como yawar ипи у yawar mayu manifiestan una valencia positiva, relacionada con la demostración del valor y de la vida. Con respecto al harawi, Kilku Warak'a nos recalca en su creación poética la vigencia de la lengua oral como medio para entender con claridad lo que escribe, pero considero que su lenguaje poético tiene menos que ver con el mundo runa y más con la dramatización de su propia existencia. En tal sentido, podría afirmar que expresa un harawi de tipo mestizo-rural-señorial. Si le restamos crédito a las grafías en el quechua y atendemos a la fonetización, podemos lograr un mejor entendimiento de su escritura y expresión, desde los signos o figuras que dan sentido a su discurso, así como desde los recursos literarios y lingüísticos que utiliza para manifestar sus sentimientos de autorreferencia. En última instancia, estamos ante un autor que, a partir de su escritura poética del quechua se distancia del habla del runa y crea un nuevo lenguaje, que recrea de manera inédita la lengua escrita, pero a la vez exige una mayor atención al lector que no es erudito. 


\section{Notas}

1. Sobre el Qhapaq Simi, véase Howard (2007) y Cerrón Palomino (1992).

2. Profundizo estos aspectos en mi tesis sobre la obra poética de Kilku Warak'a (con asesoría del Dr. Gonzalo Espino Relucé), donde considero el contexto y la significación literaria y lingüística de la producción poética publicada por Andrés Alencastre Gutiérrez.

3. Los Apus son divinidades tutelares que tienen una definición amplia: “Apu es una categoría semántica articulada por atributos definidos, los dioses/ montaña conforman un subconjunto abierto dentro del universo de entidades deificadas que reconoce el pensamiento andino" (Sánchez, 2014, p. 281).

4. Mi problema con el año de 1972, brindado por Odi Gonzáles, deriva del hecho de que él señale que Taki Parwa se publicó en 1952 (Gonzáles, 2000, p. 13), siendo indiscutible que la fecha exacta es 1955, tal y como aparece en dicho poemario. En los catálogos de la Biblioteca Nacional del Perú y de la Biblioteca de la Pontificia Universidad Católica del Perú, a diferencia de sus otros poemarios, Yawar Para es registrado como "sin fecha".

5. Primera estrofa del poema XVIII, P'ATAKISHKA / Espina que feroz muerde.

6. Sexta estrofa del poema XII, RUMIYAPUNIN /Me estoy transformando en piedra.

7. Segunda y quinta estrofa del poema XVIII, P'ATAKISHKA / Espina que feroz muerde.

8. Sexta estrofa del poema XVIII, P'ATAKISHKA / Espina que feroz muerde.

9. Otros poemas con la temática de transformación son Llakiq sonqo (XV), Wañusaq cayka (XVII) y Sapallaykitan munayki (XXXIX), entre otros.

10. Cuarta y quinta estrofa del poema XII, RUMIYAPUNIN /Me estoy transformando en piedra.

11. Colonia penal para presos políticos localizada en la selva peruana. En el poema se narra que esta muerte, provocada por enemigos yawar c'unqaqkuna (los chupasangre), conllevó a una protesta que yawarta mañantaq sipiqnikunapaq (pedía la sangre de sus asesinos).

12. Primera y quinta estrofas del poema XXII, MASHKASHAYKIN TAYTALLÁY / Te estoy buscando padre mío.

13. Segunda, cuarta y sexta estrofa del poema XXII, MASHKASHAYKIN TAYTALLÁY / Te estoy buscando padre mío.

14. Poema XV en Taki Parwa y poema XXXVII en Yawar Para.

15. Tercera y cuarta estrofa del poema XXI, KUTINKAMPULLAY / Solo 
regresa.

16. El cusqueñismo, el sentimiento de profunda identificación con el Cusco, ha cambiado en el tiempo (Nieto, 1995). Así, la reivindicación del quechua como Qhapaq Simi es más reciente, se relaciona con la necesidad de establecer una lengua normalizada, en donde la propuesta pentavocálica de la Academia es asumida con ambigüedad y controversia, debido a que como institución carece de legitimidad social, pero dispone de representación e influencia en la formulación de políticas de normalización lingüística (Howard, 2007).

17. Puede discutirse sobre la centralidad o marginalidad de Andrés Alencastre en la invención del Qhapaq Simi, masla evidencia señala que no fue periférico en su formulación original, como lo demuestra su vinculación con intelectuales cusqueñistas como Fuentes Lira, su amistad con Arguedas, y principalmente el hecho de ser uno de los fundadores de la Academia de la Lengua Quechua. Véase: Cerrón-Palomino, 1992, entre otros.

18. Primera estrofa del poema XXXVII, QHAPAQ RUNASIMI / Poderosa lengua del hombre.

19. Véase también Dumézil, 1954, donde analiza algunas de sus primeras canciones, poemas y piezas teatrales.

20. Véase también Cornejo Polar, 1994; Espino, 2010; Godenzzi, 2005.

21. Primera estrofa del poema XXX, Watuy / Presagio.

\section{Referencias bibliográficas}

Acurio, N. (1976). Literatura peruana, literatura quechua. Lima: Instituto Nacional de Cultura.

Alencastre, A. (1955). Dramas y comedias del Ande. Cusco: Editorial Garcilaso.

Alencastre, A. (1961). Kunturkanki, un pueblo del Ande. Cusco: Editorial Garcilaso.

Avendaño, A. (1993). Historia de la literatura del Qosqo. Del tiempo mítico al siglo XX. Tomo II. Qosqo: Municipalidad del Qosqo.

Cerrón-Palomino, R. (1992). Sobre el uso del alfabeto oficial quechua-aimara. En: J. C. Godenzzi Ed. y Comp.). El Quechua en Debate. Ideología, normalización y enseñanza (pp. 121-156). Cusco: Centro de Estudios Regionales Andinos Bartolomé de Las Casas.

Cornejo Polar, A. (1994). Escribir en el aire. Ensayo sobre la heterogeneidad socio-cultural en las literaturas andinas. Lima: Editorial Horizonte. 
Dumézil, G. (1954). Deux pièces "costumbristas" qhišwa de Killku Warak'a (Andrés Alencastre G.). Journal de la Société des Américanistes. Tomo 43. Recuperado de: http://www.persee.fr/doc/jsa_0037-9174_1954 num_43_1_2415

Dumézil, G. \& Alencastre, A. (1953). Fêtes et usages des Indiens de Langui (province de Canas, département du Cuzco). Journal de la Société des Américanistes, XLII, 1, 1-118. Recuperado de: http://www.persee.fr/doc/ jsa_0037-9174_1953_num_42_1_2402

Espino Relucé, G. (2010). La literatura oral o la literatura de tradición oral. Lima: Pakarina Ediciones.

Fernández, R. (1934). Aspecto literario de la Ideografía Quechua. Revista Universitaria, 67, (año XXIII, tomo II), 55-108.

Flores, J. (2011). La literatura danzada. Replanteo del folklore. En R. Robles (Ed.). Memoria y homenaje a José María Arguedas: centenario de su nacimiento (1911-2011) (pp. 123 - 141). Lima: Fondo Editorial de la Universidad Nacional Mayor de San Marcos.

Flores Galindo Segura, A. (2010). Buscando un Inca. Identidad y utopía en los Andes. Lima: Empresa Editora El Comercio.

Godenzzi, J. C. (2005). En las redes del lenguaje. Cognición, discurso y sociedad en los andes. Lima: Centro de investigación de la Universidad del Pacífico / Colegio de las Américas / Organización Universitaria Interamericana.

Gonzales, O. (1999). "Los dos lenguajes de Kilku Warak'a”. En Kilku Warak'a. Taki Parwa/22 Poemas. Cusco: Biblioteca Municipal del Cusco.

González Vigil, R. (2004). Literatura. Enciclopedia Temática del Perú. Lima: Empresa Editora El Comercio.

Gutiérrez, J. (2009). Andrés Alencastre Gutiérrez, Killku Warak'a. Recuperado de: http://cusquenos-ilustres.blogspot.com/2009/08/andres-alencastregutierrez-killku.html

Howard, R. (2007). Por los linderos de la lengua. Ideologías lingüísticas en los Andes. Lima: Instituto de Estudios Peruanos, Instituto Francés de Estudios Andinos, Pontificia Universidad Católica del Perú.

Killku Warak’a. (1955). Taki Parwa. Cusco: Editorial Garcilaso.

Killku Warak’a. (1964). Taki Ruru. Cusco: Editorial H. G. Rozas. 
Killku Warak’a. (s.f.). Yawar Para. Cusco: Editorial Garcilaso.

Lienhard, M. (1992). La voz y su huella: escritura y conflicto étnico-social en América Latina 1492- 1988. Lima: Editorial Horizonte.

Mannheim, B. (1999). El arado del tiempo: Poética Quechua y Formación Nacional. Revista Andina, 33, 1, 15-64.

Murra, J. (1983). José María Arguedas: dos imágenes. Revista Iberoamericana, XLIX(122), 43-54.

Nieto, L. (1995). Tres momentos en la evolución del cusqueñismo. Márgenes. Encuentro y Debate, 13/14, 113-161.

Nieto, L.; Vargas, J. \& Itier, C. (2011). Qosqo Qhechwasimipi Akllasqa Rimaykuna. Antología Quechua del Cusco. Cusco: Municipalidad Provincial del Cusco.

Noriega, J. (2011). Escritura quechua en el Perú. Lima: Pakarina Ediciones.

Rowe, W. (1983). Arguedas: el narrador y el antropólogo frente al lenguaje. Revista Iberoamericana, XLIX, 122, 97-109.

Sánchez Garrafa, R. (2014). Apus de los cuatro Suyus. Construcción del mundo en los ciclos mitológicos de las deidades montaña. Lima: Centro de Estudios Regionales Andinos Bartolomé de Las Casas, Instituto de Estudios Peruanos. 